The Hydrophobic Effect Drives the Recognition of Hydrocarbons by an Anionic Metal-Ligand Cluster

Shannon M. Biros, Robert G. Bergman and Kenneth N. Raymond

Contribution from the Department of Chemistry, University of California and Lawrence Berkeley National Laboratory, Berkeley, California 94720. 


\title{
The Hydrophobic Effect Drives the Recognition of Hydrocarbons by an Anionic Metal-Ligand Cluster ${ }^{1}$
}

\author{
Shannon M. Biros, Robert G. Bergman* and Kenneth N. Raymond* \\ Contribution from the Department of Chemistry, University of California, Berkeley, California 94720-1460.
}

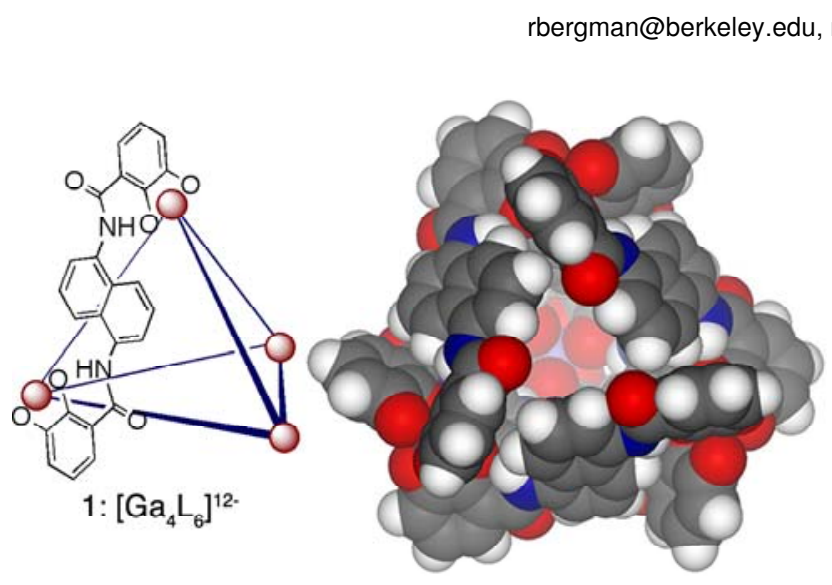

We have developed and studied water-soluble $\left[\mathrm{M}_{4} \mathrm{~L}_{6}\right]^{12-}$ metal ligand clusters such as 1 (Figure $1 ; \mathrm{M}=\mathrm{Ga}(\mathrm{III}), \mathrm{L}=1,5$ biscatecholamide naphthalene). These clusters contain a hydrophobic cavity of approximately 300-500 $\AA^{3}{ }^{2,3}$ Surveys of potential guests have led to the finding that the clusters are capable of encapsulating a variety of monocations including tetraalkylammonium salts, ${ }^{4}$ reactive phosphonium species $^{5}$ and half-sandwich ruthenium complexes. ${ }^{6,7}$ Early studies ${ }^{8}$ with the $\mathrm{Et}_{4} \mathrm{~N} \subset\left[\mathrm{Ga}_{4} \mathrm{~L}_{6}\right]^{11-}$ complex did not show neutral guest encapsulation; since then, it has been generally assumed that because of the highly anionic character of these clusters, encapsulation requires a positively charged guest.

Recently, we found that the $\left[\mathrm{Ga}_{4} \mathrm{~L}_{6}\right]^{12-}$ host catalyzes the hydrolysis of orthoformates ${ }^{9}$ and acetals ${ }^{10}$ in an enzyme-like manner. In these studies, kinetic evidence suggested that the initial event in the

Figure 1. Schematic (left) and CPK model (right, CPK colors) of $\left[\mathrm{Ga}_{4} \mathrm{~L}_{6}\right]^{12-}$ metal-ligand cluster $\mathbf{1}$. catalytic cycle involved the binding of the neutral substrate to give a transient orthoformate- or acetal-cluster intermediate. ${ }^{9,10}$ Intrigued by these results, we sought to determine whether we could directly observe the binding of neutral guest molecules by this highly charged, anionic host. We now report that this cluster binds neutral, hydrophobic guests, including saturated hydrocarbons, ${ }^{11,12}$ in aqueous solution, with both size and shape selectivity. ${ }^{13}$

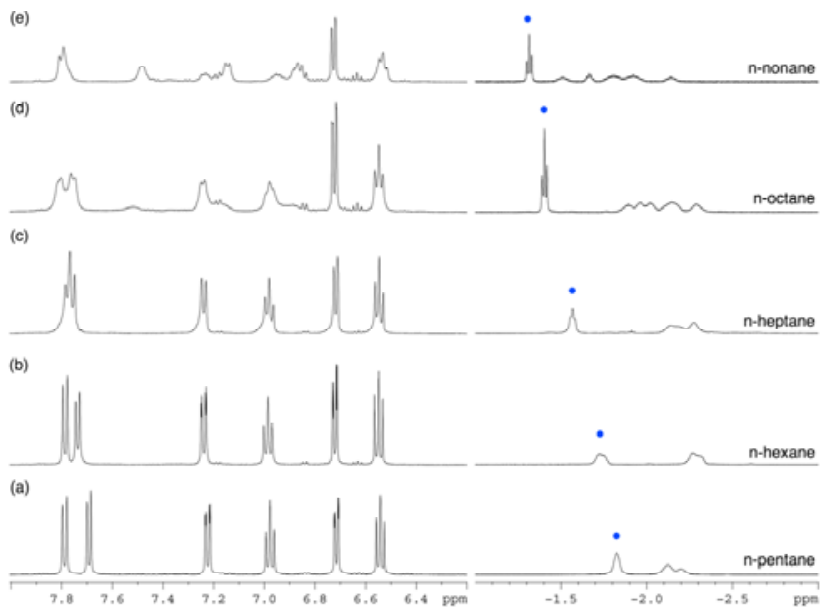

Figure 2. ${ }^{1} \mathrm{H}$ NMR spectra of $\left[n \text {-alkane } \subset \mathrm{Ga}_{4} \mathrm{~L}_{6}\right]^{12-}$ complexes $\left(\mathrm{D}_{2} \mathrm{O}\right.$, $\mathrm{pD} \approx 12,500 \mathrm{MHz})$; downfield portion = host resonances; upfield portion $=$ bound guest resonances; $(\mu)$ : bound guest methyl groups.

information about the structure of the guests in these complexes can be gleaned from the ${ }^{1} \mathrm{H}$ NMR spectra. With the smaller alkanes (pentane-heptane), the guest resonances are relatively broad, suggestive of an intermediate rate of guest exchange, while the host resonances are sharp and well defined. In the case of the longer alkanes, octane and nonane, the opposite trend is observed relatively sharp bound guest and broad host resonances. We envision two possible explanations for this observation. First, as the alkyl chain gets larger, the orientation of the bound alkane becomes increasingly static, inducing a higher degree of asymmetry in the host ligand protons. This hypothesis is supported by the gradual downfield shift of the bound guest methyl group as the alkane length increases, indicative of coiling of the alkyl chains such that the methyl groups point progressively towards the center of the host cavity. ${ }^{14}$ Alternatively, portions of the alkane guest could be extending into and out of the host cavity rapidly on the ${ }^{1} \mathrm{H}$ NMR time scale, resulting in
Upon addition of a series of $n$ - and cycloalkanes to host $\mathbf{1}$, the formation of kinetically stable 1:1 host-guest complexes were observed by ${ }^{1} \mathrm{H}$ NMR (Figures 2 and 3). These experiments were carried out by layering the alkane phase directly onto the aqueous solution of host 1, enabling extraction of the hydrophobic guest into water. Characteristic upfield shifts are seen for bound guest resonances with $\Delta \delta$ 's ranging between 2 and $4 \mathrm{ppm}(\Delta \delta=$ exterior resonance - interior resonance). Complexation is attributed to the hydrophobic effect, along with a relatively small enthalpic gain from $\mathrm{CH}-\pi$ interactions between guest and host.

For the series of $n$-alkanes, $n$-pentane through $n$-nonane are suitable guests for this system, while decane is not, presumably because it is too large to fit inside the cavity (Figure 2). Some

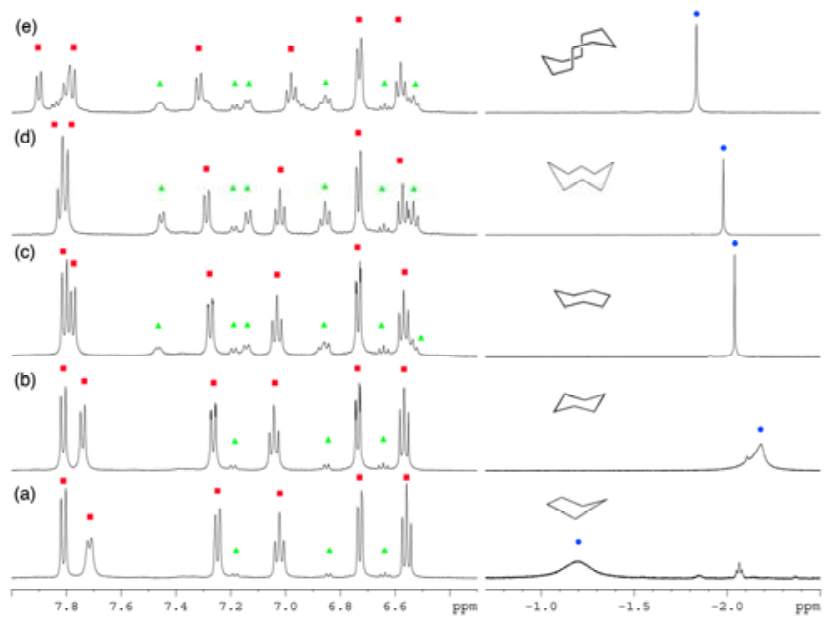

Figure 3. Aromatic (host) and upfield (bound guest) portions of the ${ }^{1} \mathrm{H}$ NMR spectra $\left(500 \mathrm{MHz}, \mathrm{D}_{2} \mathrm{O}, \mathrm{pD} \approx 12\right)$ of a series of cycloalkanes bound to $\mathrm{Ga}_{4} \mathrm{~L}_{6}$ host 1 ; $(\mu)$ bound guest; $(1 / 4)$ bound host; $($ ) free (empty) host. 
broadened host resonances. ${ }^{15}$ However, the latter explanation can be ruled out since in that case we would expect to observe broadening of the guest resonances as well.

Host 1 also binds the series of cyclic hydrocarbons cyclopentane through cyclooctane (Figure 3 ). Significantly, although the linear $n$ decane is not a guest for this system, the more compact cyclodecane does bind. The host-guest complexes of cyclopentane and cyclohexane give one broad resonance for bound guest protons, while the larger cycloheptane, cyclooctane and cyclodecane are represented by one sharp peak.

Other cyclic hydrocarbons bound by 1 in a 1:1 host-guest fashion are the 10-membered rings adamantane, exo- and endodicyclopentadiene ${ }^{16}$ and the decalins (Figure 4). The host-guest complex with adamantane gives a simple set of resonances for bound guest, since the guest and host both have purely rotational $T$ symmetry. However, the ${ }^{1} \mathrm{H}$ NMR spectra of the other cyclic C10 isomers are much more complicated. The $\left[\mathrm{Ga}_{4} \mathrm{~L}_{6}\right]^{12-}$ complexes of both dicyclopentadiene isomers have a complex set of resonances corresponding to bound guest resulting from the lower symmetry of these ring systems. The $\left[(\text { trans-decalin }) \subset \mathrm{Ga}_{4} \mathrm{~L}_{6}\right]^{12-}$ (where $\subset$ denotes encapsulation) complex shows nine sets of sharp resonances for bound guest, integrating to two protons each. This can be explained by the absence of a mirror plane in trans-decalin when it is bound in the cluster cavity. For the related cis-decalin complex, only broad peaks corresponding to bound guest are observed.

The relative binding affinities of the $n$ - and cycloalkanes were determined by ${ }^{1} \mathrm{H}$ NMR direct competition experiments (see supporting information). For both series of alkanes the binding affinity increases as the chain length is increased if the solubility difference of each alkane is taken into account. ${ }^{17}$ This observation is consistent with the hydrophobic effect as the driving force for these complexation reactions: as the guest size is increased the amount of "high-energy" water molecules that are released into solution increases, resulting in a larger entropic gain. We also compared the $n$ alkanes with their cyclic isomers (C5-C8) and found that the linear alkanes have a higher affinity for host $\mathbf{1}$ - again consistent with the desolvation of a larger surface area.

In conclusion, we have reported the complexation of a series of

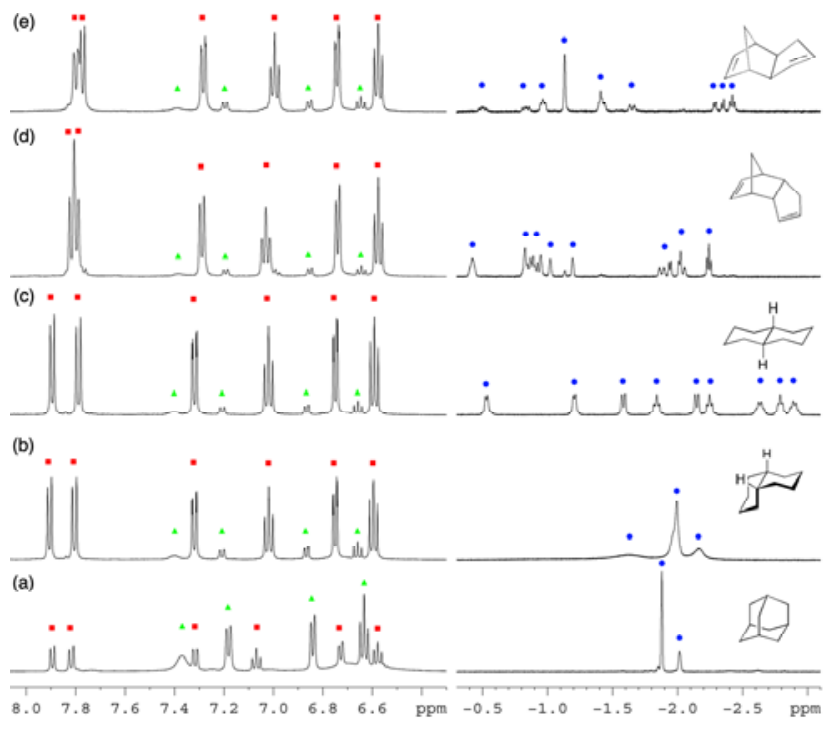

Figure 4. Aromatic (host) and upfield (bound guest) portions of the ${ }^{1} \mathrm{H}$ NMR spectra $\left(500 \mathrm{MHz}, \mathrm{D}_{2} \mathrm{O}, \mathrm{pD} \approx 12\right)$ of a series of cyclodecanes bound to $\left[\mathrm{Ga}_{4} \mathrm{~L}_{6}\right]^{12-}$ host $\mathbf{1} ;(\mu)$ bound guest; (1/4) bound host; $(\mathrm{)})$ free (empty) host.

neutral $n$-alkanes and cycloalkanes by a metal-ligand cluster bearing a 12 - charge. The driving force for these binding events is attributed to the hydrophobic effect: the release of highly organized water molecules around a non-polar solute into bulk solvent water. ${ }^{18,19}$ This observation speaks to the strength of the hydrophobic effect in small molecule recognition both in synthetic receptors and biological systems. $^{20}$

Acknowledgements. We gratefully acknowledge financial support from the Director, Office of Science, Office of Advanced Scientific Computing Research, Office of Basic Energy Sciences (U.S. Department of Energy) under contract DE-AC02-05CH11231. We also thank M.D. Pluth, C.J. Hastings and H.J. Van Anda (The Scripps Research Institute) for helpful discussions.

Supporting Information. Full experimental details for the preparation of host-guest complexes and competition experimental data. This material is available free of charge via the Internet at http://pubs.acs.org.

Paper number 37 in the series Coordination Number Incommensurate Cluster Formation. For the previous paper in the series see: Pluth, M.D.; Bergman, R.G.; Raymond, K.N. J. Am. Chem. Soc., in press.

Caulder, D. L.; Raymond, K. N. J. Chem. Soc., Dalton Trans. 1999, 1185-1200.

Caulder, D. L.; Powers, R. E.; Parac, T. N.; Raymond, K. N. Angew. Chem. Int. Ed. 1998, 37, 1840-1843.

Caulder, D. L.; Brückner, C.; Powers, R. E.; Künig, S.; Parac, T. N.; Leary, J. A.; Raymond, K. N. J. Am. Chem. Soc. 2001, $123,8923-8938$.

Ziegler, M.; Brumaghim, J. L.; Raymond, K. N. Angew. Chem. Int. Ed. 2000, 39, 4119-4121.

Fiedler, D.; Pagliero, D.; Brumaghim, J. L.; Bergman, R. G.; Raymond, K. N. Inorg. Chem. 2004, 43, 846-848.

Fiedler, D.; Leung, D. H.; Bergman, R. G.; Raymond, K. N. J. Am. Chem. Soc. 2004, 126, 3674-3675.

Parac, T. N.; Caulder, D. L.; Raymond, K. N. J. Am. Chem. Soc. 1998, 120, 8003-8004

Pluth, M. D.; Bergman, R. G.; Raymond, K. N. Science 2007, 316, 85-88.

Pluth, M. D.; Bergman, R. G.; Raymond, K. N. to be submitted for publication.

Gibb, C. L. D.; Gibb, B. C. J. Am. Chem. Soc. 2006, 128, 16498-16499.

Hooley, R. J.; Biros, S. M.; Rebek, J., Jr. Chem. Commun. 2006, 509-510.

Ferguson, S. B.; Sanford, E. M.; Seward, E. M.; Diederich, F. J. Am. Chem. Soc. 1991, 113, 5410-5419.

Palmer, L. C.; Rebek, J., Jr. Org. Lett. 2005, 7, 787-789.

Tiedemann, B. E. F.; Raymond, K. N. Angew. Chem. Int. Ed. 2007, 46, 4976-4978.

Nelson, G. L.; Kuo, C.-L. Synthesis 1975, 105-106.

McAuliffe, C. J. Phys. Chem. 1966, 70, 1267-1275.

Marmur, A. J. Am. Chem. Soc. 2000, 122, 2120-2121.

Tanford, C. Science 1978, 200, 1012-1018.

Further detailed analysis of the complexities of this system will be investigated and reported in the form of a full paper. 